\title{
A dança como produto à venda em casas noturnas: um mapeamento do terreno mercadológico
}

\author{
Eliane Regina Crestani Tortola* \\ Larissa Michelle Lara**
}

\begin{abstract}
Resumo: O estudo, orientado pela etnografia multissituada, problematiza as relações sociais estabelecidas no contexto de casas noturnas na cidade de Maringá-PR de modo a identificar como a dança é apropriada nesses espaços e se os frequentadores a identificam como principal atrativo de consumo. Os resultados atentam para a presença da dança na maioria dos espaços urbanos de lazer noturno investigados e para sua prática alienada, reforçada, muitas vezes, pelas músicas midiáticas e consumo etílico, intensificados pelas investidas da indústria da diversão.
\end{abstract}

Palavras-chave: Dança; Atividades de Lazer; Antropologia cultural

\section{INTRODUÇÃO}

Incursionar pelas manifestações corporais tematizadas pela educação física não é atentar apenas para sua gestualidade técnica e expressiva. Significa considerar seu contexto e jogo tensional num emaranhado de relações altamente complexas. A dança, como uma dessas manifestações, coloca-se como conhecimento denso que transcende a temporalidade do gesto dada sua dimensão histórica, artística, valorativa e de construção de sentidos e significados, os quais tomam forma por meio da ação humana.

\footnotetext{
‘Escola de Educação Física da Universidade Estadual de Goiás. Goiânia, GO. Brasil E-mail: eli-tortola@hotmail.com

“Universidade Estadual de Maringá (UEM). Maringá, PR, Brasil. E-mail: Imlara@hotmail.com
} 
Existe um mundo da dança diferente do que é praticado nas academias e clubes e que salta aos olhos dos profissionais desse campo de conhecimento quando seus alunos reivindicam o aprendizado das "danças que todo mundo dança". Trata-se de um mundo onde as relações estabelecidas não estão pautadas no domínio técnico e de aprendizado de novas gestualidades, pelo menos não de forma consciente, mas no ensejo de viver a liberdade, a conquista, $o$ simulacro e a fantasia. Esse mundo é representado pelo contexto das casas noturnas, espaço de mercadorização de bens culturais como música e dança e que compõem o cenário urbano de lazer noturno. Motivados à experiência da dança por meio das músicas de entretenimento, os alunos requerem, durante as aulas, os sons que integram seu cotidiano, sob o argumento de terem visto pessoas dançando de determinada maneira em locais destinados à prática da dança no tempo de lazer. É nesse tempo-espaço do lazer, entendido como tempo liberado das obrigações cotidianas (MARCELLINO, 2006) e caracterizado densamente pelo interesse social, que as danças da moda são disseminadas, além, é claro, da veiculação em meios de comunicação, como a televisão. Mas é nas casas noturnas que os sujeitos interagem, criam desejos, trocam informações acerca do que está acontecendo "no momento" e sobre as músicas mais dançantes, os tipos de danças praticadas, entre outros trocadilhos constantemente levados aos profissionais que tratam desse campo. A dança, portanto, passa a se configurar como produto de consumo, exposto como mercadoria atrelada às músicas da moda e aos artistas da mídia.

Partindo da necessidade de conhecer o universo simbólico das casas noturnas e entender como as danças se manifestam nesse contexto é que a cidade de Maringá-PR, local de residência das pesquisadoras, com ampla oferta de casas de dança, foi a escolhida para o desenvolvimento da pesquisa. A etnografia multissituada (MARCUS, 1998), marcada por conexões, associações e supostas relações entre o objeto investigativo e os atores sociais, tornou-se o caminho orientador para condução da pesquisa. De acordo com o 
autor, a etnografia multissituada é o produto com base no conhecimento de diferentes intensidades e qualidades, um exercício de mapeamento de terreno e não uma representação holística.

A dança no contexto das casas noturnas é o objeto do nosso estudo, produzida em locais diferentes e de formas variadas. Em meio à gama de ritmos dançantes disponíveis à venda nas casas noturnas de Maringá-PR é que se tornou fundante o reconhecimento desses espaços, também chamados aqui de equipamentos de lazer ${ }^{1}$, buscando identificar como a dança é apropriada e se ela constitui o principal atrativo de consumo dos frequentadores. De modo específico, esse "como" a dança é apropriada conduzia a reflexões acerca dos elementos que poderiam interferir nessa prática, como a música e o consumo etílico, o que gerou a necessidade de observar se a apropriação da dança guardava relação com o tipo de música e bebida consumidos e se poderia contribuir para intensificar uma prática manipuladora do gosto.

Para o desenvolvimento da pesquisa foi necessário incursionar por 11 casas noturnas, que se diferenciam em estilos musicais e que recebem consumidores de classes sócio-econômicas, gênero e idades distintas. A escolha das casas se deu por acessibilidade, dado que nem todos os estabelecimentos dessa natureza se disponibilizaram a atender-nos em nosso estudo. Demandou um acompanhamento noite a noite, registrando imageticamente, anotando em diário de campo impressões e percepções do ritual de entretenimento noturno, por cerca de 6 meses. Os dados foram categorizados de acordo com elementos emergentes durante as observações, revendo ideias iniciais, repensando-as, reavaliando-as de modo que novas percepções emergissem desse processo.

A investigação encontra-se sistematizada em dois momentos. No primeiro, dança e música são discutidas como produto por meio de reflexões sobre indústria cultural, tendo os teóricos Adorno e Horkheimer (1985) papel central no debate. No segundo momento é apresentado o mapeamento mercadológico por meio das

\footnotetext{
${ }^{1}$ Termo cunhado por Marcellino (2006) para designar o espaço destinado às práticas urbanas.
} 
informações e análises advindas da coleta de dados nas casas noturnas na cidade de Maringá-PR, realizadas sob o olhar da etnografia multissituada, de Marcus (1998), momento em que são debatidas questões acerca da dança como produto consumido.

Com isso, espera-se trazer dados que possam alicerçar discussões contemporâneas sobre o usufruto da dança no tempo de lazer e sobre as formas pelas quais ela é subsumida pela sociedade de consumo, mais especificamente, pela indústria da diversão, transformando-se em fonte alienadora ao invés de meio transformador da vida do ser humano. Tais apontamentos são centrais ao se pensar a dança no campo da educação física, uma vez que ela se dá em espaços formais e não formais em estreita relação com o cotidiano, modificando-o e sendo por ele modificado. Sendo o processo de formação do sujeito dado de diferentes formas e em diversos contextos sociais, a problematização da vida passa a ser condição essencial de uma educação transformadora.

\section{SE ELES DANÇAM, EU DANÇO... CONFORME A MÚSICA.: REFLEXÕES ACERCA DAS INVESTIDAS MIDIÁTICAS}

Os diferentes atores sociais, adeptos do funk, sertanejo, samba, forró, rock, punk, pop-rock, entre outros estilos musicais, dançam as músicas "mais tocadas", ou seja, as músicas da moda. São elas que, por meio de suas letras, instigam comportamentos e ideias, formando juízos de valor, mecanizando os sujeitos que se emudecem e não se contrapõem às imposições da indústria da diversão. As músicas de entretenimento determinam a frequência e garantem o público que lota as pistas de dança, embalado pelas canções mais tocadas nas rádios, independente do estilo musical.

Os sujeitos, por vezes, se entregam ao simulacro de uma canção conduzida por uma letra que reflete aquilo que eles sentem (ou devem sentir); ou a maneira como devem agir diante de determinadas situações, a exemplo das músicas erotizadas, que instigam e apelam 
para a sexualidade, orientando as ações dos frequentadores das casas noturnas. Há, ainda, canções que instigam ao consumo do álcool, embaladas por refrões que se repetem até que o sujeito passe a cantarolar e agir de acordo com o objetivo previsto na música.

Algumas músicas, entre muitas tocadas no contexto das casas noturnas, e que fazem parte do repertório da noite, dizem o que Adorno (1999, p. 70) explica como sendo um "prazer do momento e da fachada de variedade" que "transforma-se em pretexto para desobrigar o ouvinte de pensar no todo, cuja existência está incluída na audição adequada e justa; sem grande oposição, o ouvinte se converte em simples comprador e consumidor passivo". O autor ainda afirma que se trata de "[...] um círculo vicioso fatal: o mais conhecido é o mais famoso, e tem mais sucesso. Consequentemente, é gravado e ouvido sempre mais, e com isso se torna mais conhecido" (ADORNO, 1999, p. 75). Para o frankfurtiano, isso se dá não só em relação às "músicas ligeiras"2, mas também na mercadorização das "músicas sérias"3. Afirma que tais músicas são submetidas à lei de consumo pelo preço do seu conteúdo e que as "músicas sérias" são ouvidas assim como se consome qualquer mercadoria adquirida no mercado. Ainda, explica que os dois tipos de músicas estão subordinados às bases de venda. São mercadorias, ou seja, passam pelo mesmo processo mercantil de oferta e procura.

O consumo da dança nas casas noturnas se submete às músicas de sucesso, em que os objetos se portam como sujeitos, enquanto que todos os que eram os antigos sujeitos - os consumidores - tornamse objetificados. Eis um processo de caráter manipulador que "não consegue imaginar de nenhum modo o mundo diferente do que ele é", a "completa incapacidade de o sujeito levar adiante experiências diretas em razão de seu realismo exagerado" (CENCI, 2008, p. 427).

\footnotetext{
${ }^{2}$ Termo utilizado por Adorno (1999) para designar as músicas da mídia, de sucesso fugaz e passageiro.

${ }^{3}$ Termo cunhado por Adorno (1999) para designar as músicas eruditas, de pouca veiculação midiática.
} 
Fica elucidativo que as reflexões propostas por Adorno e Horkheimer (1985) ilustram o quanto os sujeitos, ao consumirem um bem cultural, como dançar uma música, por exemplo, o fazem com os sentidos viciados para alimentar o que é angustiante e alienante, vivendo uma alegria momentânea, alimentando a indústria da diversão e privando-se da livre expressão artística.

\section{CASAS NOTURNAS COMO ESPAÇO PARA A VENDA DA DANÇA: O CENÁRIO ETNOGRÁFICO}

A análise de um dado fenômeno sob o olhar antropológico fazse, comumente, por meio da pesquisa etnográfica, entendida por Lévi-Strauss (1975, p. 14) como um método que consiste na "observação e análise de grupos humanos considerados em sua particularidade". De acordo com Laplantine (1991, p. 150), a pesquisa etnográfica é "a experiência de uma imersão total" no campo investigativo, de modo a viver a tendência principal da cultura estudada, uma estratégia de pesquisa que implica a descrição densa do fenômeno, das relações estabelecidas e das manifestações culturais investigadas em um único campo de investigação.

A etnografia multissituada, uma das formas de etnografia, oferece, segundo Marcus (1998), a oportunidade de perguntar que tipo de saberes locais são distintamente sondados. Ao invés de fazer uma etnografia local única, a etnografia multissituada parte de uma etnografia de múltiplos locais, que tem por relação o mesmo objeto, nesse caso, a dança, levando em consideração inúmeros aspectos. Desse modo, identificamos como o mesmo fenômeno é percebido em locais diversos e vivenciado por pessoas com gostos e preferências diferenciadas, de classes sociais distintas.

Enfatizando a importância da utilização da etnografia multissituada em pesquisas de cunho cultural, Silvano (2002, p. 4) orienta que 
É evidente que hoje todos os lugares se encontram em relação direta ou mediatizada com o exterior, e que, por isso, a produção de cultura implica sempre a relação com outros lugares. Para dar conta dessa realidade, a concepção do espaço tem de se socorrer de noções que integrem múltiplos lugares.

As orientações de Silvano (2002) corroboram com as explicações de Marcus (1998, p. 90) para a aplicação desse método que utiliza "correntes, caminhos, fios conjuntores ou justaposições" de locais em que o etnógrafo estabelece alguma forma de presença, tendo o compromisso explícito de associação ou ligação entre os locais, o que em nosso estudo se dá por meio do objeto "dança".

Desse modo, o trabalho etnográfico multissituado resultou na construção de um conjunto de dados organizado em dois momentos: 1) olhar sobre o cenário de consumo da dança, reconhecendo o público frequentador, os ritmos veiculados e o nível socioeconômico do espaço urbano de lazer noturno, disseminado no cotidiano como casa noturna, boate e, comumente, "balada", de modo a identificar o tempo-espaço para a venda desse bem cultural; 2) reconhecer os elementos que mais se evidenciam nesse contexto no sentido de mapear o campo mercadológico da dança em Maringá-PR, identificando os espaços em que ela se coloca como atrativo principal e como as músicas midiáticas influenciam no processo de sua comercialização. O Quadro 1 apresenta as casas noturnas pesquisadas durante o período de sete meses, bem como suas características principais, tais como ritmo, público e nível socioeconômico. 


\begin{tabular}{|c|c|c|c|}
\hline Casa noturna & Público & $\begin{array}{c}\text { Classe } \\
\text { socioeconômica }\end{array}$ & Ritmos predominantes \\
\hline Nite Club ${ }^{4}$ & $\begin{array}{l}\text { Jovens universitários } \\
\text { e adultos. }\end{array}$ & Classe alta & $\begin{array}{l}\text { Samba rock, cibercultura- } \\
\text { remixes e funk }\end{array}$ \\
\hline Luxurius & $\begin{array}{l}\text { GLBT - Gays, lésbicas, } \\
\text { bissexuais e transexuais }\end{array}$ & $\begin{array}{l}\text { Classe média- } \\
\text { alta }\end{array}$ & Cibercultura-remixes \\
\hline \begin{tabular}{|l} 
Aquaticus \\
Bar \\
\end{tabular} & $\begin{array}{l}\text { Universitários, } \\
\text { jovens e adultos }\end{array}$ & Classe média & Samba e sertanejo \\
\hline Juscelino & $\begin{array}{l}\text { Universitários, } \\
\text { jovens e adultos }\end{array}$ & $\begin{array}{l}\text { Classe média- } \\
\text { alta }\end{array}$ & Sertanejo \\
\hline Porto Café & $\begin{array}{l}\text { Universitários, jovens } \\
\text { e adultos }\end{array}$ & $\begin{array}{l}\text { Classe média- } \\
\text { alta }\end{array}$ & $\begin{array}{l}\text { Samba rock, pop rock, } \\
\text { sertanejo, cibercultura- } \\
\text { remixes }\end{array}$ \\
\hline \begin{tabular}{|l|} 
Clube do \\
Vovô
\end{tabular} & $\begin{array}{l}\text { Jovens, adultos e } \\
\text { idosos/ }\end{array}$ & $\begin{array}{l}\text { Classe média- } \\
\text { baixa }\end{array}$ & Dança de salão \\
\hline $\begin{array}{l}\text { Estância } \\
\text { Gaúcha } \\
\end{array}$ & $\begin{array}{l}\text { Jovens, adultos } \\
\text { e idosos }\end{array}$ & $\begin{array}{l}\text { Classe média- } \\
\text { baixa }\end{array}$ & Dança de salão \\
\hline Atlântico & $\begin{array}{l}\text { Jovens, } \\
\text { adultos e } \\
\text { idosos }\end{array}$ & $\begin{array}{l}\text { Classe média- } \\
\text { baixa }\end{array}$ & Dança de salão \\
\hline G8 Eventos & $\begin{array}{l}\text { Pré adoloescentes, } \\
\text { Adolescente e jovens }\end{array}$ & Classe baixa & Funk \\
\hline MPB & $\begin{array}{l}\text { Universitários, } \\
\text { jovens e adultos }\end{array}$ & $\begin{array}{l}\text { Classe média- } \\
\text { alta }\end{array}$ & $\begin{array}{l}\text { Sertanejo, pop rock, samba } \\
\text { rock. }\end{array}$ \\
\hline Tribos Bar & Jovens e adultos & Classe média & $\begin{array}{l}\text { Rock, alternativo, heavy } \\
\text { metal. }\end{array}$ \\
\hline
\end{tabular}

Quadro 1 - Perfil das casas noturnas de Maringá. Fonte: Autor

Em Maringá, as casas noturnas funcionam como ponto de encontro de diferentes sujeitos, momento em que fazem da dança protagonista, coadjuvante ou algo indiferente, independente da localização geográfica. Em alguns desses locais, a superlotação provocada pela ânsia do proprietário na obtenção de lucro, independente da condição adequada do espaço, inviabiliza ou dificulta a prática dançante. $\mathrm{O}$ sujeito que procura a dança como atividade de lazer, ao se deparar com essa realidade, busca locais que ofertem condições para que a dança possa ser consumida.

A presença de ambos os sexos nas casas noturnas, até mesmo na frequentada por homossexuais, em que pessoas do mesmo sexo se relacionam, valoriza os espaços como determinantes de afetividades, namoros, amizades, e, no caso da dança, de troca de experiências, aprendizado de novas performances e de demonstrações das competências e habilidades dançantes dos sujeitos frequentadores. Assim, pesquisar a dança em casas noturnas é,

${ }^{4}$ Nome original da casa, confirmado com o gerente do estabelecimento.

Movimento, Porto Alegre, v. 17, n. 02, p. 137-154, abr/jun de 2011. 
também, impregnar-se por uma racionalidade criadora e por estímulos sensoriais próprios desses espaços, estando atento ao que cada local provoca.

Cada casa noturna cria um clima que instiga, o que conduz à determinação de comportamentos e à configuração de sentidos/ significados peculiares às relações estabelecidas. Esse clima é produzido por meio de recursos imagéticos, como banners, placas, murais, quadros na parede, e objetos decorativos. Outro recurso é o luminoso, com a utilização de raios coloridos, estrobo ${ }^{5}$ e globo espelhado. Além disso, uma penumbra é produzida por meio de uma máquina de fumaça.

O clima é gerado pelos atores sociais frequentadores desses locais e pelo espaço físico. Conforme Carlos (2001, p. 11), "o lugar onde se manifesta a vida, o espaço é condição, meio e produto da realização da sociedade humana em toda a sua multiplicidade". Compõe-se de experiência, permite a vida, deixando marcas, projetando utopias e imaginários. A autora ainda esclarece que

[...] a sociedade constrói um mundo objetivo; na prática socioespacial, esse mundo se revela em suas contradições, em um movimento que aponta um processo de reprodução das relações sociais (que se realiza como relação espaço-temporal) (CARLOS, 2001, p. 11-12).

Durante as incursões foi possível perceber que alguns frequentadores da Estância Gaúcha e da Luxurius também frequentavam o Aquaticus Bar, porém, esporadicamente. Já os frequentadores do Tribos Bar e da G8 Eventos não foram vistos em outras casas noturnas em que as incursões se deram. Isto demonstra que não existe um padrão em termos de fidelidade a uma só casa por parte de alguns frequentadores, dado que na Estância Gaúcha, o ritmo predominante é o vanerão, e na Luxurius, as músicas eletrônicas é que movem o público. Os frequentadores do Nite Club não são

\footnotetext{
${ }^{5} \mathrm{Aparelho}$ eletrônico luminoso, presente nas casas noturnas que veiculam a música eletrônica. Trata-se de um instrumento que pisca ininterruptamente, provocando nos sujeitos a sensação de movimentação, mesmo que esteja parado.
} 
vistos em outras casas, especialmente as de baixo nível socioeconômico, como é o caso da G8 eventos.

Com vistas a identificar o atrativo que leva os consumidores a se tornarem frequentadores de determinada casa noturna, buscamos categorizar os elementos que mais se evidenciaram no decorrer das incursões em campo, sendo eles: dançar; consumo etílico; ouvir música; encontro afetivo e afirmação de status social. O quadro 2 apresenta os elementos que se evidenciaram muito (M) e os que pouco $(\mathrm{P})$ aparecem durante as inserções em campo.

\begin{tabular}{|c|c|c|c|c|c|}
\hline $\begin{array}{c}\text { Casa } \\
\text { noturna }\end{array}$ & Dançar & $\begin{array}{c}\text { Consumo } \\
\text { etílico }\end{array}$ & $\begin{array}{l}\text { Ouvir } \\
\text { música }\end{array}$ & $\begin{array}{c}\text { Encontro } \\
\text { afetivo }\end{array}$ & $\begin{array}{c}\text { Afirmação } \\
\text { de status } \\
\text { social }\end{array}$ \\
\hline Nite Club & $\mathrm{P}$ & M & $\mathrm{P}$ & M & $\mathrm{M}$ \\
\hline Luxurius & M & M & $\mathrm{P}$ & M & $\mathrm{P}$ \\
\hline $\begin{array}{c}\text { Aquaticus } \\
\text { Bar }\end{array}$ & M & M & $\mathrm{P}$ & M & $\mathrm{P}$ \\
\hline Juscelino & $\mathrm{P}$ & M & M & M & M \\
\hline Porto Café & $P$ & M & M & $\mathrm{P}$ & M \\
\hline $\begin{array}{c}\text { Clube do } \\
\text { Vovô }\end{array}$ & M & $P$ & $\mathrm{P}$ & M & $P$ \\
\hline $\begin{array}{l}\text { Estância } \\
\text { Gaúcha }\end{array}$ & M & $P$ & $\mathrm{P}$ & $\mathrm{P}$ & $\mathrm{P}$ \\
\hline Atlântico & M & $\mathrm{P}$ & $\mathrm{P}$ & $\mathrm{P}$ & $\mathrm{P}$ \\
\hline G8 Eventos & M & $\mathrm{P}$ & $\mathrm{P}$ & M & $\mathrm{P}$ \\
\hline MPB & $\mathrm{P}$ & M & M & M & M \\
\hline Tribos Bar & M & M & M & $\mathrm{P}$ & $\mathrm{P}$ \\
\hline
\end{tabular}

Quadro 2 - Elementos atrativos ao consumo em casas noturnas na cidade de Maringá-PR. Fonte: Autora

A tabela mostra que, das 11 casas noturnas investigadas, sete tem a dança como elemento que se evidencia nas relações estabelecidas pelos sujeitos, sendo atrativo na escolha do equipamento de lazer nas noites urbanas de Maringá-PR. Todas as casas investigadas possuem pista de dança, espaço teoricamente destinado a essa finalidade. Entretanto, não são todas as casas que dão às pistas essa destinação. 
Na Estância Gaúcha, Clube do Vovô e Atlântico a pista de dança, além de dimensão, ampliada, possui regras de uso, embora implícitas, como: não invada a pista de dança enquanto houver pessoas dançando lá, a menos que se disponha a dançar também. Não existe nada escrito sobre isso, pois a normativa é tácita. Se alguém estaciona na pista, é arrastado pela multidão dançante, sobretudo em músicas do estilo sertanejo ou vanerão. Isso se explica por serem esses os ritmos fortemente veiculados pela mídia. Nesse aspecto, fica evidente que a música midiática influencia, também nessas casas noturnas, a prática e o consumo da dança pelos atores sociais envolvidos.

Nas demais casas - Aquaticus, G8 eventos, Luxurius e Tribos Bar - apesar de possuírem pista de dança e seus frequentadores utilizarem o espaço para esse fim, não existe uma regra quanto à sua não ocupação durante a "balada". A todo momento pessoas circulam por essa delimitação espacial, seja apenas para observar a banda tocar, atrapalhando a movimentação dançante das pessoas no local, seja com bebida alcoólica na mão. No entanto, foi observado que durante a roda punk - Tribos Bar - as pessoas não invadem o centro do círculo fechado pelos frequentadores por medo de serem atingidos por golpes violentos, característicos dessa manifestação gestual denominada $m o s h^{6}$. Isso faz com que os sujeitos fiquem na pista, porém, ao redor da roda.

Estar na pista de dança e não dançar é comportamento frequente observado nas casas em que a dança não ocorre com muita evidência, como é o caso do Nite Club, Juscelino, Porto Café e MPB Bar. Nessas casas, o que ocorre é a pista tomada por frequentadores que se excedem no consumo etílico. $\mathrm{O}$ entorpecimento proporcionado pelo álcool deixa o sujeito à vontade, em estado de vertigem. No caso das casas em que a dança aparece como prática evidente, o consumo de álcool potencializa a performance do sujeito, aumentando os aspectos violentos, negativos e deturpadores do consumo desse bem cultural. Caracterizados

\footnotetext{
${ }^{6} \mathrm{~A}$ expressão mosh é utilizada no Brasil para designar o ritual que parte da euforia da roda punk, em que o sujeito atravessa o público, sobe ao palco e, aclamado pelos pares, salta em direção a eles na certeza de ser amparado pelos seus anônimos colegas de pista.
} 
principalmente pelo consumo etílico, os atores sociais lotam bares e casas noturnas no intuito de beber em demasia. Peuker, Fogaça e Bizzaro (2006, p. 194) explicam que

O uso de álcool entre universitários também pode ser favorecido de forma indireta. Estudantes influenciam-se mutuamente em termos de beber pela modelagem, imitação ou reforçamento do comportamento de beber. A seleção de colegas, a escolha do tipo de substância, o padrão de uso e a forma como o consumo de substâncias de seus pares é percebida parecem interagir neste processo. As normas comportamentais estabelecidas em relação ao beber podem servir para justificar os comportamentos extremados observados entre eles. Sabe-se também que universitários tendem a superestimar tanto a aceitabilidade quanto o comportamento de beber propriamente dito de seus pares.

O consumo etílico está presente nas composições de muitas músicas que embalam as danças dos sujeitos no lazer noturno, os quais se comportam e dançam conforme gostos e necessidades padronizadas. Muitos também são adeptos do pagode e forró, frequentam as casas de músicas eletrônicas e procuram acompanhar as novidades do universo cibernético. Ouvir música, portanto, é um dos elementos que atrai principalmente os jovens a esses espaços, embora não configura a maioria em nossa pesquisa, dado que apenas quatro casas noturnas apresentam pouca evidência dessa categoria. A ação de ouvir música está relacionada à ausência de consumo da dança, ao encontro com amigos e à influencia da mídia que determina o tipo de música que os sujeitos devem ouvir.

Adorno (1999, p. 85) explica o fenômeno que modifica o arranjo musical para torná-lo mais atraente afirmando que as músicas tocadas nas casas noturnas já são músicas aligeiradas ou músicas de entretenimento; caíram no gosto da massa. O filósofo chama esse fenômeno de "ditadura social" que "confirma seu poder e a sua glória pelo selo que é impresso em tudo quanto cai na engrenagem 
de seu maquinismo". Ao discutir o jazz, Adorno já falava dos "arranjos coloridos" que promoviam modificações para atrair. Tais constatações na contemporaneidade nos levam a perguntar o que diria o pensador se ouvisse as atuais músicas eletrônicas, que ao cair no gosto popular ou quando já estão quase esquecidas, são modificadas, manipuladas, cortadas, recortadas e coladas em remendos? Tais alterações musicais referem-se ao que o autor define como "embelezamento artificial", acrescentando que "o processo de coisificação radical produz a sua própria aparência de imediaticidade e intimidade" (ADORNO, 1999, p. 84).

As músicas aguçam os sentidos e influenciam a prática da afetividade, promovendo o encontro entre os sujeitos e as relações amorosas que atraem os frequentadores de sete casas noturnas, das 11 investigadas. Tanto as casas com muita evidência no consumo de dança quanto as que não possuem essa predominância tendem ao encontro afetivo. Porém, o que caracterizou essa categoria foi a observação das ditas "paqueras" que ocorriam tanto por meio da aproximação direta, como pela dança. Por vezes os sujeitos se aproveitam do momento em que está dançando para atrair o outro. Em alguns casos é percebido que uma única pessoa envolve-se com mais de um indivíduo na mesma noite, como é o caso da Luxurius e G8 eventos, onde o apelo erótico é fortemente marcado pelas danças e músicas que remetem ao ato sexual. O consumo exacerbado de álcool também facilita a aproximação, especialmente dos jovens universitários que parecem necessitar desse artifício para o sucesso na conquista amorosa, já que o álcool provoca estado de liberdade, aumentando a coragem dos sujeitos em partir para as investidas afetivas.

Em algumas casas noturnas os sujeitos tendem a afirmar-se em sua condição socioeconômica elevada, como ocorrem em quatro espaços incurcionados. Nesses locais, exibir o carro novo à frente da boate, a roupa de marca ou os acessórios (relógios, joias, calçados), bem como consumir as bebidas destiladas mais caras são tidos como modos de apresentação à sociedade de sua condição 
financeira, passaporte para a entrada do indivíduo na chamada "alta sociedade". Jovens e adultos se relacionam por meio de interesses sociais de pertencimento a esse dado grupo, e, por vezes, não frequentam outros locais.

É comum observar pessoas conversando com um copo de destilado na mão, as quais raramente dançam e, por vezes, nem ouvem música. Treinam os olhares para observar o local em busca da oportunidade do encontro afetivo e do prazer momentâneo. Os presentes em camarotes ${ }^{7}$ compõem o cenário de espaços urbanos de lazer onde a dança não se encontra como atividade predominante.

Ramos (2008, p. 83) esclarece que essa condição de fruição e prazer está distante de ser uma experiência estética, sendo, portanto,

[...] imitação compulsiva, característica da Indústria Cultural e reveladora de indivíduos subjetivamente esvaziados, que buscam no que lhes é oferecido pronto e facilitado a identificação narcísica com objetos manipulados ou a submissão passiva a falsos imperativos. Ao buscar no prazer com o mundo empírico uma substância para o ego e na transcendência do gozo um sentido para a vida, o indivíduo reproduz um mundo em que o prazer negado se tornou possível às custas de sua infantilização e em que as tensões entre particular e todo foram superadas às custas do sacrifício do particular. Nos dois casos, o sujeito se aliena na posição de objeto.

Ou seja, o sujeito é livre para dançar o que ele quiser e consumir os bens culturais que lhe convém. O problema está no que ele tem acesso e no "como" tem acesso ao que lhe é oferecido, pois geralmente suas escolhas são determinadas e sua liberdade é vigiada. Mas, nem por isso ele deixa de viver o momento de prazer necessário à sua condição humana.

Desse modo, a procura pela dança como prática de lazer nas casas noturnas dá-se, na maioria das vezes, por meio das investidas da indústria cultural, a qual determina as danças e músicas que

${ }^{7}$ Espaços destinado aos frequentadores de classe social elevada, denotadora de status.

Movimento, Porto Alegre, v. 17, n. 02, p. 137-154, abr/jun de 2011. 
devemos dançar. Em alguns casos, o consumo da dança é quase inexistente, especialmente quando os equipamentos de lazer são pontos de encontro para determinar o pertencimento a um dado grupo socioeconômico ou apenas para o prazer vertiginoso provocado pelo consumo etílico.

Foi possível constatar em nosso estudo que a dança ainda é, nas casas noturnas da cidade de Maringá-PR, um dos principais atrativos para a frequência dos atores sociais nesses locais. Sua prática, porém, não está atrelada ao fazer artístico e transformador e, sim, a um processo de consumo alienado, em que os sujeitos apenas dançam as músicas da moda, sendo por elas influenciados em comportamentos e gestualidades, como é o caso dos ritmos funk, pagode e sertanejo. As casas que não têm a dança como produto principal voltam-se principalmente para o consumo etílico e encontro afetivo, não atraindo, desse modo, os indivíduos que buscam na dança o prazer provocado pela prática dessa modalidade em seu momento de lazer noturno, mesmo que de maneira alienada.

\section{Considerações Finals}

O mapeamento do cenário mercadológico da dança envolveu incursões pelas casas noturnas de Maringá-PR por meio da realização de etnografia em multilocais. As inserções em campo trouxeramnos a constatação de que a dança está presente na maioria dos espaços urbanos de lazer noturno, porém não marcada pelo sentido de fruição artística, mas impregnada pela indústria da diversão. Tal constatação trouxe caminhos norteadores para a problemática central dessa pesquisa, qual seja, se a dança é o principal produto de consumo nesses espaços e se ocorre a influência das músicas midiáticas nesse processo como manipuladora do gosto pelas práticas dançantes.

Assim como ocorre no mecanismo de venda de produtos industrializados, existem também danças para todos os públicos, para os que "gostam" de funk, sertanejo, pagode, rock, música eletrônica, vanerão, entre outros. O que determina a escolha são as relações entre o indivíduo e a mídia, sendo que a última veicula o produto 
ininterruptamente até que o consumidor o experimente, por curiosidade, e passe a necessitar do prazer imediato proporcionado pelo êxtase e vertigem momentâneos que oferece.

Da incursão pelo campo foi possível apreender que além da dança, as casas noturnas oferecem o consumo etílico como prática de diversão, sendo também um dos principais atrativos desses locais. Identificamos que onde predomina a dança como principal produto de consumo, o álcool é coadjuvante e não existe a presença de DJs que chamem a atenção para a relação entre as músicas eletrônicas e a deturpação da dança, manifestada por meio do apelo erótico e sexualidade exacerbada.

Entender o processo de apropriação da dança como bem cultural que sofre as investidas midiáticas, bem como as relações que se desenrolam no cenário urbano de lazer noturno, traz desafios. É necessário entender esse processo de modo a nele intervir e desafiálo, conduzindo os sujeitos à reflexão acerca do que está posto. Não basta olhar com olhos indignados. É preciso, sim, conhecer essa realidade que traz implicações ao campo educacional, por meio de uma ação voltada para o entendimento desse mecanismo de banalização das danças, promovido pelo processo da indústria da diversão, intervindo, formando e fazendo mediações. 
Dance as a product to sell in nightclubs: a mapping the field marketing

Abstract: The study, led by multi-placed ethnography, questions the social relations in the context of nightclubs in the city of Maringa-PR in order to identify how dance is appropriate in these spaces and if the patrons identify the main attraction of consumption. The results call attention to the presence of dance in most urban entertainment nightly investigated and disposed of his practice, reinforced often by the music media and alcohol consumption by intensified assaults on the entertainment industry.

Keywords: dancing. leisure activities. anthropology. cultural.

\section{La danza como un producto para vender en los clubes nocturnos: um mapeo de lo campo de comercialización \\ Resumen: El estudio, dirigido por la etnografía multi- puesto, pregunta las relaciones sociales en el contexto de los clubes nocturnos en la ciudad de Maringá-PR con el fin de identifican cómo la danza es apropiada en estos espacios y si los patrones identifican la como el principal atractivo de consumo. Los resultados llaman la atención sobre la presencia de la danza en la mayoría de entretenimiento urbano nocturno investigadas y resueltas de su práctica, reforzada a menudo por los medios de comunicación la música y el consumo de alcohol, intensificado por los ataques de la industria del entretenimiento.}

Palabras-clave: baile. actividades recreativas. antropología cultural.

\section{REFERÊNCIAS}

ADORNO, T. W.; HORKHEIMER, M. Dialética do esclarecimento. Rio de Janeiro: Zahar, 1985.

ADORNO, T. W. O Fetichismo na música e a regressão da audição. In: Textos escolhidos. São Paulo: Nova Cultura. 1999.

CARLOS, A. F. A. Espaço-tempo na metrópole: a fragmentação da vida cotidiana. São Paulo: Contexto, 2001. 
CENCI, A. V. Semiformação versus aptidão à experiência: implicações ético-políticas dos escritos adornianos sobre educação. In: SGRÓ, M. (Org.). Teoría crítica de la sociedad, educación, democracia y ciudadania. Tandil: Universidade Nacional Del Centro de La Provincia de Buenos Aires, 2008. p. 417-430.

LAPLANTINE, François. Aprender antropologia. São Paulo: Brasiliense, 1991.

LÉVI-STRAUSS, Claude. Antropologia cultural. Rio de Janeiro: Tempo Brasileiro, 1975.

MARCELLINO, N. C. Lazer, espaço urbano e transversalidade. In: CARVALHO, J. E. (Org.). Lazer no espaço urbano: transversalidade e novas tecnologias. Curitiba: Champagnat, 2006. p. 71-81.

MARCUS, G. E. Ethnography in/of the world system: the emergence of multi-sited ethnography. In: MARCUS, G. E. Ethnography through Thick/Thin. Princeton: Princeton University, 1998.

PEUKER, A. C.; FOGAÇA, J.; BIZARRO, L.. Expectativas e beber problemático entre universitários. Revista Psicologia, Brasília, v. 22 n. 2, p. 193-200, maio/ago. 2006. Disponível em: <http://www.scielo.br/pdf/ptp/v22n2/a09v22n2.pdf>. Acesso em: 27 dez. 2010.

RAMOS, C. Indústria cultural, consumismo e a dinâmica das satisfações no mundo administrado. In: DURÃO, F. A.; ZUIN, A.; VAZ, A. F. (org.). A Indústria Cultural Hoje. São Paulo: Boitempo, 2008.

SILVANO, F. José e Jacinta nem sempre vivem nos mesmos lugares:... Ethnologia: Antropologia dos processos identitários. Lisboa: Cosmos, 2002.

Endereço para correspondência:

Eliane R.C. Tortola

Rua 18, $n^{\circ} 21$, Centro

CEP: $76550-000$

Porangatu-GO

Recebido em: 25.04.2011

Aprovado em: 14.05.2011 
